Louisiana State University

LSU Digital Commons

$1-1-2013$

\title{
EPFR formation from phenol adsorption on Al2O3 and TiO2: EPR and EELS studies
}

\author{
Matthew C. Patterson \\ Louisiana State University \\ Nathan D. Keilbart \\ Louisiana State University \\ Lucy W. Kiruri \\ Louisiana State University \\ Chad A. Thibodeaux \\ Louisiana State University \\ Slawo Lomnicki \\ Louisiana State University
}

See next page for additional authors

Follow this and additional works at: https://digitalcommons.Isu.edu/physics_astronomy_pubs

\section{Recommended Citation}

Patterson, M., Keilbart, N., Kiruri, L., Thibodeaux, C., Lomnicki, S., Kurtz, R., Poliakoff, E., Dellinger, B., \& Sprunger, P. (2013). EPFR formation from phenol adsorption on Al2O3 and TiO2: EPR and EELS studies. Chemical Physics, 422, 277-282. https://doi.org/10.1016/j.chemphys.2012.12.003

This Article is brought to you for free and open access by the Department of Physics \& Astronomy at LSU Digital Commons. It has been accepted for inclusion in Faculty Publications by an authorized administrator of LSU Digital Commons. For more information, please contact ir@lsu.edu. 


\section{Authors}

Matthew C. Patterson, Nathan D. Keilbart, Lucy W. Kiruri, Chad A. Thibodeaux, Slawo Lomnicki, Richard L. Kurtz, E. D. Poliakoff, Barry Dellinger, and Phillip T. Sprunger 


\title{
EPFR Formation from Phenol adsorption on $\mathrm{Al}_{2} \mathrm{O}_{3}$ and $\mathrm{TiO}_{2}$ : EPR and EELS studies
}

\author{
Matthew C. Patterson ${ }^{\mathrm{a}}$, Nathan D. Keilbart ${ }^{\mathrm{a}, \mathrm{c}}$, Lucy W. Kiruri ${ }^{\mathrm{b}}$, Chad A. Thibodeaux ${ }^{\mathrm{b}}$, Slawo \\ Lomnicki $^{\mathrm{b}}$, Richard L. Kurtz ${ }^{\mathrm{a}}$, E. D. Poliakoff ${ }^{\mathrm{b}}$, Barry Dellinger ${ }^{\mathrm{b}}$, and Phillip T. Sprunger ${ }^{\mathrm{a}}$ \\ aDepartment of Physics and Astronomy, Louisiana State University, Baton Rouge, Louisiana \\ 70803, USA \\ bDepartment of Chemistry, Louisiana State University, Baton Rouge, Louisiana 70803, USA \\ 'Department of Mechanical Engineering, Brigham Young University-Idaho, Rexburg, ID 83460, \\ USA
}

\begin{abstract}
We have examined the formation of environmentally persistent free radicals (EPFRs) from phenol over alumina and titania using both powder and single-crystal samples. Electron paramagnetic resonance (EPR) studies of phenol adsorbed on metal oxide powders indicates radical formation on both titania and alumina, with both oxides forming one faster-decaying species (lifetime on the order of 50-100 hours) and one slower-decayng species (lifetimes on the order of 1000 hours or more). Electron energy loss spectroscopy (EELS) measurements comparing physisorbed phenol on single-crystal $\mathrm{TiO}_{2}(110)$ to phenoxyl radicals on the same substrate indicate distinct changes in the $\pi-\pi^{*}$ transitions from phenol after radical formation. The identical shifts are observed from EELS studies of phenoxyl radicals on ultrathin alumina grown on $\mathrm{NiAl}(110)$, indicating that this shift in the $\pi-\pi^{*}$ transition may be taken as a general hallmark of phenoxyl radical formation.
\end{abstract}

\section{INTRODUCTION}

Recent experimental evidence has demonstrated the formation of environmentally persistent free radicals (EPFRs) associated with airborne particulate matter generated in combustion reactions. Laboratory studies have demonstrated the formation of EPFRs from substituted benzene precursors on systems such $\mathrm{Cu}$ (II) oxide and $\mathrm{Fe}$ (III) oxide supported on silica used as model fly ash, with half-lives of hours to days under ambient conditions [1,2], and virtually indefinite lifetimes under vacuum. Ab initio calculations attribute this stability and low reactivity to resonance stabilization including both carbon- and oxygen-centered radical structures [3]. Evidence of EPFRs has been found in soil samples from a Superfund wood treating site [4], and it has been demonstrated that EPFRs derived from the reaction of 2monochlorophenol (2-MCP) on $\mathrm{CuO} /$ silica particles can form reactive oxygen species in

\footnotetext{
(C) 2012 Elsevier B.V. All rights reserved.

Corresponding author: Matthew C. Patterson Louisiana State University Department of Physics and Astronomy 202 Nicholson Hall, Tower Dr. Baton Rouge, LA 70803 mpatt15@tigers.lsu.edu (225) 578-1388 (phone) (225) 578-5855 (departmental fax). (mpatt15@tigers.1su.edu); (kei07001@byui.edu); (lkirur1@tigers.1su.edu); (cthib19@tigers.1su.edu); (slomni1@1su.edu); (rlkurtz@1su.edu); (epoliak@1su.edu); (barryd@1su.edu); (phils@1su.edu)

Publisher's Disclaimer: This is a PDF file of an unedited manuscript that has been accepted for publication. As a service to our customers we are providing this early version of the manuscript. The manuscript will undergo copyediting, typesetting, and review of the resulting proof before it is published in its final citable form. Please note that during the production process errors may be discovered which could affect the content, and all legal disclaimers that apply to the journal pertain.
} 
aqueous solutions $[5,6]$. These EPFR-containing particles in turn have been demonstrated to lead to oxidative stress and increased cell death in both animal [7] and human [8] tissues.

Precursors such as phenol, 2-MCP, catechol, 1,2-dichlorobenzene, and other substituted benzenes have been proposed to form EPFRs over metal oxides at elevated temperatures (375-775 K) by a mechanism involving initial physisorption, elimination of $\mathrm{H}_{2} \mathrm{O}$ or $\mathrm{HCl}$ to chemisorb to the metal ion, and electron transfer from the precursor to the metal oxide resulting in the reduction of the metal accompanied by EPFR formation [1]. The formation of EPFRs from several aromatic precursors has been experimentally shown through electron paramagnetic resonance (EPR) spectroscopy on both $\mathrm{CuO}$ [1] and $\mathrm{Fe}_{2} \mathrm{O}_{3}$ [2] particles supported on silica. The EPR spectra of the dosed precursors show three common features an F-center formed in the metal oxide after electron transfer from the precursor, and either a phenoxyl-type or semiquinone-type radical (see Fig. 1 for a generic mechanism of phenoxyl radical formation). As further evidence of this proposed mechanism, Cu K-edge XANES spectroscopy of 2-MCP, chlorobenzene, and 1,2-dichlorobenzene adsorbed on micron-sized $\mathrm{CuO}$ supported on silica directly shows the reduction of $\mathrm{Cu}(\mathrm{II}) \mathrm{O}$ to a mixture of $\mathrm{Cu}(\mathrm{II})$, $\mathrm{Cu}(\mathrm{I})$, and small amounts of $\mathrm{Cu}(0)$ after exposure to these precursors at elevated temperature [9].

In this study, we used electron paramagnetic resonance (EPR) spectroscopy and electron energy loss spectroscopy (EELS) to investigate the mechanisms of EPFR formation from aromatic precursors on the surface of other well-characterized metal oxides of interest, specifically $\mathrm{TiO}_{2}$ and $\mathrm{Al}_{2} \mathrm{O}_{3}$. Alumina is, along with silica, the highest concentration species in complex combustion systems [10-12], making it a system of interest along with copper oxides and other transition metal oxides. EPR studies clearly demonstrate the formation of EPFRs on these systems, while EELS studies on single-crystal alumina and $\mathrm{TiO}_{2}$ guide a more fundamental understanding of the changes in the electronic structure and morphology of both the metal oxide and the adsorbed molecule. The combination of techniques leads us toward a more detailed atomic-scale picture of the radical formation.

\section{EXPERIMENTAL METHODS}

\section{A. Electron Paramagnetic Resonance Spectroscopy}

All EPR measurements were performed using a Bruker EMX-2.0/2.7 EPR spectrometer with dual cavities, X-band, $100 \mathrm{kHz}$, and microwave frequency, $9.53 \mathrm{GHz}$. The spectra were obtained at room temperature. The typical operating parameters were: microwave power 1 $\mathrm{mW}$, modulation amplitude $4 \mathrm{G}$, sweep width $200 \mathrm{G}$, time constant $40.960 \mathrm{~ms}$, and sweep time $167.7 \mathrm{~s}$.

The particulate samples (-alumina and titania) were exposed to the vapors of phenol using a custom-made vacuum exposure system. The system consisted of a vacuum gauge, dosing vial port, equilibration chamber, and 2 reactors. Prior to adsorption, each sample was oxidized in air in situ at $725 \mathrm{~K}$. Vapors of the molecular adsorbates were introduced into the equilibration chamber at the desired pressure ( 10 Torr), and the particles were exposed to the adsorbate vapors at $505 \mathrm{~K}$ for $5 \mathrm{~min}$. Once the exposure was completed, the port and dosing tube were evacuated for $1 \mathrm{~h}$ at the dosing temperature and a pressure of $10^{-2}$ Torr. The reactor was then sealed under vacuum, and the sample was cooled to room temperature prior to EPR measurements.

To determine the persistency (combination of stability and lack of reactivity) of the EPFRs, kinetic studies were performed. EPFR/particle samples were continuously exposed to room air at ambient temperature, and the EPR signal was measured periodically to determine the radical concentration as a function of time. To determine the concentration of radicals 
(spins/gram), the area of the EPR absorption peak in each sample was compared to that of a known amount of a DPPH (2,2-diphenyl-1-picrylhydrazyl) standard (1 radical/molecule). Radical decay kinetic experiments in air are based on an assumed reaction with molecular oxygen:

$$
\mathrm{R}+\mathrm{O}_{2}=\text { Product. }
$$

For reaction rate calculations, a first order kinetic expression was used:

$$
-d R / d t=k[R]
$$

where $\left.k=\mathrm{K}_{\mathrm{O}} \mathrm{O}_{2}\right]$ for excess oxygen conditions (pseudo zero order in oxygen concentration). The $1 / \mathrm{e}$ half-life decay is calculated from the first order decay $t_{1 / e}=1 / k$, where $k$ is a slope of the linear regression to the integrated kinetic differential equation

$$
\ln \left(R / R_{0}\right)=-k t
$$

For the purpose of clarity the radical decays were plotted on a semi-logarithmic scale to yield a straight-line fit.

\section{B. Electron Energy Loss Spectroscopy}

EELS experiments were performed using single-crystal rutile $\mathrm{TiO}_{2}(110)$ from commercial vendors and ultrathin alumina grown by oxidizing single-crystal $\mathrm{NiAl}(110)$ using standard methods [13-15]. Experiments were performed in a UHV system with base pressure $10^{-10}$ Torr consisting of two chambers connected by a gate valve. The preparation chamber contained a sputter gun, leak valves to dose various gases, LEED, and a single-pass cylindrical mirror analyzer with coaxial electron gun for Auger electron spectroscopy measurements. The EELS chamber contained an LK Technologies LK2000 EELS spectrometer. Samples were checked for cleanliness by looking for clean and sharp LEED patterns and ensuring that Auger spectra showed no adventitious carbon or other species.

To dose our chosen EPFR precursor, solid phenol was loaded into Pyrex tubes attached to standard leak valves through a mini-conflat flange and purified by freeze-pump-thaw cycles, after which sublimated vapor was able to be dosed into the chamber. For high pressure $\left(10^{-3}\right.$ Torr) dosing, used for exposures of $10^{6}$ Langmuir or greater $\left(1 \mathrm{~L}=10^{-6}\right.$ Torr $\left.\bullet \mathrm{s}\right)$, samples were transferred into a separately pumped cell (base pressure $\sim 5 \times 10^{-6}$ Torr) that could be isolated from the main chamber to avoid contaminating the UHV system. The cell was equipped with a sample stage that could be radiantly heated with a nearby glass-enclosed tungsten filament, with temperature measured by a type $\mathrm{K}$ thermocouple in contact with the sample stage. When dosing at elevated temperature, samples were first heated under vacuum and maintained at constant temperature for 10 minutes before dosing the desired quantity of gas. After dosing, we transferred the sample back to the main chamber when the pressure in the cell dropped to $\sim 10^{-5}$ Torr.

Vibrational and low-level electronic excitations of the clean and prepared surfaces were measured with high-resolution electron energy loss spectroscopy (HREELS) using an LK 2000 spectrometer. Primary beam energies were chosen to be either 7 or $30 \mathrm{eV}$ for recording vibrational spectra and electronic excitations, respectively, with energy resolution of order 8-10 meV for vibrational spectra and $\sim 30 \mathrm{meV}$ for electronic excitations (measured by the width of the elastically scattered electron beam). Experiments were performed in both specular (incident beam angle equal to exiting beam angle) and off-specular (incident beam angle different from exiting beam angle) in order to probe both dipole-active and Raman- 
active vibrational modes, respectively. Unless otherwise noted, EELS spectra displayed here were normalized to the height of the elastic peak, with offsets added for clarity.

\section{RESULTS AND DISCUSSION}

\section{A. EPR studies of phenol adsorption on particulate titania and alumina}

Adsorption of phenol on the surface of both -alumina and titania resulted in formation of surface species with a distinct observable paramagnetic signal (cf. table 1 and Fig. 2). Adsorption of phenol over -alumina produced a paramagnetic signal typical of that observed earlier for transition metal oxides, with a g-value of 2.0043 and peak width of 9.6 gauss. Such signals are typical for surface adsorbed aromatic radicals [1,2]. The broadness of the peak suggested the formation of a combination of more than one type of paramagnetic species. The mechanism of radical formation developed for metal oxides suggests formation of phenoxyl type radicals, in line with observed g-values. In contrast, adsorption of phenol on the titania surface resulted in very narrow signal with a peak width of $\sim 5$ gauss indicative of the presence of a single type of radical species with a radical yield $\sim 10$ times higher than alumina. The observed g-value of 2.0032 is characteristic of the radical with an electron present on a carbon atom with a nearby oxygen.

A closer look at the decay curves of the EPFRs on both surfaces confirms the differences between the adsorption on titania and alumina surfaces. Though no significant peak width or $\mathrm{g}$ value change was detected upon the exposure of titania-bound radicals to air, two different decay behaviors were observed with a 1/e half-lives of 4.3 days and 57.4 days. Two explanations are plausible: i) two different radical species with a very similar spectral parameters are present, though with distinguishable decays or ii) two types of surface sites on alumina are responsible for stabilization of radical. Since a relatively low $g$ value was observed, the EPFR signal may have a contribution from a phenyl radical, resulting from the flat interaction of the aromatic ring with the titatnia surface and $\mathrm{p}$-d electron back donation.

Radicals associated with the -alumina surface revealed two separate decay profiles: one with a 1/e half life of only $\sim 2.5$ days and a second with a 1/e half-life $\sim 40$ days. A correlation between the decay profiles and changes in $\mathrm{g}$ values and peak width could be observed. The $\mathrm{H}_{\mathrm{p}-\mathrm{p}}$ gradually decreased from 9.6 to 8.7 gauss with a simultaneous increase in g-value from 2.0043 to 2.0046 . This suggested a low g-value component of the paramagnetic signal was decaying relatively rapidly. The width of the remaining signal suggested a superposition of two species. Based on the shift in the g-value towards 2.0046, the species remaining on the surface were likely phenoxyl and even more persistent o-semiquinone type radicals. Semiquinone radicals result from a reaction between the chemisorbed phenoxyl radical and a surface lattice oxygen atom from the metal oxide [1,2]. Upon electron transfer between the newly formed surface bidentate species and the metal center, a semiquinone radical is formed.

\section{B. EELS studies of phenol adsorption}

1. Single-crystal $\mathrm{TiO}_{2}(\mathbf{1 1 0})$-In order to determine the changes in electronic structure of adsorbed phenol that indicate radical formation, it is essential to understand the electronic structure of the neutral phenol molecule. Fig. 3 shows the electronic excitations characteristic of phenol adsorbed at low temperature on both partially reduced and fully oxidized $\mathrm{TiO}_{2}(110)$ The presence of oxygen vacancies on the clean $\mathrm{TiO}_{2}$ surface is signaled by the loss peak at $0.8 \mathrm{eV}$ (blue spectrum), and these vacancies can be filled, producing a fully stoichiometric $\mathrm{TiO}_{2}$ surface, by dosing $\sim 200 \mathrm{~L}$ of $\mathrm{O}_{2}$ at room temperature after sputtering and annealing in vacuum (black spectrum). Surprisingly, after dosing phenol at 90 $\mathrm{K}$, a clear difference between the reduced and oxidized $\mathrm{TiO}_{2}(110)$ surfaces is apparent. 
When phenol is dosed on the reduced surface, shown in the pink spectrum in Fig. 3, we observe loss peaks consistent with those measured for physisorbed benzene on alumina [16] and for phenol in the gas phase [17], which have been assigned to various allowed transitions between molecular orbitals. On the oxidized surface, shown in red, we see a large peak at lower energy $(\sim 3 \mathrm{eV})$ which does not appear in the gas phase data from the literature. So while we can be confident that the phenol adsorbed on reduced $\mathrm{TiO}_{2}(110)$ at $90 \mathrm{~K}$ represents intact physisorbed phenol, the nature of the bonding between phenol and fully oxidized $\mathrm{TiO}_{2}(110)$ is not yet understood even at low temperature.

With a spectrum from physisorbed phenol on reduced $\mathrm{TiO}_{2}(110)$ as a guide, we can now examine the behavior of phenol deposited under EPFR-forming temperature and pressure conditions to determine any features in the electronic structure that may be hallmarks of the radical species. In Fig. 4, we see few differences between phenol adsorbed at $90 \mathrm{~K}$ (pink) and the same sample allowed to warm to room temperature (black). The peak at $6.48 \mathrm{eV}$ is still the most prominent peak in the spectrum (due to a $\pi-\pi^{*}$ excitation from phenol), and the others from physisorbed phenol are still apparent, although in the room temperature sample they are convoluted with the usual features from the reduced $\mathrm{TiO}_{2}(110)$ - a weak peak due to oxygen vacancies at $0.8 \mathrm{eV}$ and the onset of interband transitions starting at $3.4 \mathrm{eV}$. We attribute this to the desorption of all but a single layer of phenol when the sample is warmed to room temperature, so that EELS is able to probe features from both the adsorbate and substrate. Interestingly, a peak at about $2.85 \mathrm{eV}$ appears in the room temperature spectrum which is absent from both the spectrum of clean $\mathrm{TiO}_{2}$ and multilayer physisorbed phenol at $90 \mathrm{~K}$. This appears at roughly the same position in energy as the anomalous peak observed from phenol adsorption at $90 \mathrm{~K}$ on fully oxidized $\mathrm{TiO}_{2}(110)$ in Fig. 3 above, which may indicate some feature of the phenol- $\mathrm{TiO}_{2}$ physisorption that is not shared by the bonding of subsequent phenol multilayers.

For our purposes, the most important data is the topmost spectrum in Fig. 4 showing the results of $10^{6} \mathrm{~L}\left(10^{-3}\right.$ Torr, $\left.1000 \mathrm{~s}\right)$ phenol exposed at $525 \mathrm{~K}$. We now do not resolve many distinct peaks, but see a continuum of states starting at approximately $2.2 \mathrm{eV}$. The distinct peak we can see at $6.18 \mathrm{eV}$ appears to correspond to the most intense allowed transition from the physisorbed phenol, which has been assigned to the ${ }^{1} \mathrm{~A}_{1 \mathrm{~g}} \rightarrow{ }^{1} \mathrm{E}_{1 \mathrm{u}}$ transition from gas phase data [17], but it is shifted $0.3 \mathrm{eV}$ to lower energy with respect to the same peak measured from physisorbed phenol at both $90 \mathrm{~K}$ and $300 \mathrm{~K}$. In combination with the EPR data shown in Fig. 1 from phenol adsorption on particulate titania, it would appear that this shift in the $\pi-\pi^{*}$ excitation is the hallmark of the formation of a phenoxyl radical. We do not resolve additional peaks that might be indicative of two different radical species as suggested by Fig. 2(b), but this is consistent with the finding of a single g-value as observed in Fig. 2(a). Density functional calculations to elucidate the differences in molecular orbital structure between the phenol molecule and the phenoxyl radical are an ongoing topic of research.

Examining the low-energy region of the spectra $(<1 \mathrm{eV}$ loss energy) in Fig. 4 provides a hint at what may be happening to the titania after the adsorption of phenol. The spectrum from clean $\mathrm{r}-\mathrm{TiO}_{2}(110)$ shows a loss peak at $0.8 \mathrm{eV}$ characteristic of oxygen vacancies, as mentioned above. The spectrum of multilayer physisorbed phenol at $90 \mathrm{~K}$ shows much less intensity in this region, which is consistent with the lack of any observed interband transitions from titania in the spectrum - the EELS probes the multilayer adsorbate but does not "see" the substrate. In both the spectrum from physisorbed phenol at room temperature and the spectrum from $10^{6} \mathrm{~L}$ phenol dosed at $525 \mathrm{~K}$, we see substantial intensity in the spectrum below $2 \mathrm{eV}$. This may be indicative of electron transfer between the adsorbed phenol and titania, with the extra electron occupying the "defect" state that is visible in the clean spectrum. 
2. Ultrathin $\mathrm{Al}_{2} \mathrm{O}_{3}$ grown on single-crystal $\mathrm{NiAl}(110)$-We have similarly investigated the adsorption behavior of phenol on alumina at high temperature and pressure using EELS. Because bulk alumina is a wide band gap insulator, we prepare a model thin film of alumina by oxidizing a $\mathrm{NiAl}(110)$ crystal; using standard methods, this forms a wellordered alumina film approximately $8 \AA$ thick [13-15], which can be studied using electron spectroscopic methods that require conducting or semiconducting samples. The blue spectra in Fig. 5 show electronic excitations typical of this ultrathin alumina film at room temperature, with a broad loss peak at approximately $1.6 \mathrm{eV}$ due to defects in the film and the onset of allowed interband (band-gap) transitions starting at $7.5 \mathrm{eV}$. This is practically ideal, as it provides a window in which to observe electronic excitations from phenol, which typically lie in the region from $3-7 \mathrm{eV}$. It is apparent from Fig. 5a that, after dosing $10^{6} \mathrm{~L}$ phenol at $525 \mathrm{~K}$ as we did on $\mathrm{TiO}_{2}(110)$, we observe electronic losses in the alumina band gap region.

If we examine the appropriate energy region in more detail (Fig. 5b), we observe the existence of a loss peak at $6.18 \mathrm{eV}$ after the adsorption of $10^{6} \mathrm{~L}$ phenol at $525 \mathrm{~K}$, which agrees with the shifted $\pi-\pi^{*}$ transition seen in the identical exposure of phenol on $\mathrm{TiO}_{2}(110)$ in Fig. 4 above. We see also that the allowed interband transitions from the alumina thin film are no longer visible in the dosed sample, though whether this indicates an alteration in the alumina film itself or merely that it has been completely covered by phenol is not clear from these spectra alone. This new loss peak at $6.18 \mathrm{eV}$ may again be attributed to the presence of a phenoxyl radical. We do not clearly resolve additional peaks that might indicate the additional presence of the o-semiquinone radical indicated by the EPR spectra presented in Fig. 1, but this must be taken as a null result rather than a statement that no additional radical species are present. The lower radical yield over alumina shown in Fig. 1 and Table 1 may explain our inability to resolve the presence of two unique species using EELS.

If we choose a lower incident beam energy and examine only the energy losses from 0-500 $\mathrm{meV}$, we can resolve energy losses due to vibrational modes of both the substrate and any adsorbates. The blue spectrum in Fig. 6 shows the vibrational losses from the clean alumina thin film, with strong surface phonon loss peaks at 50, 80, and $103 \mathrm{meV}$ typical of the alumina formed by oxidation of $\mathrm{NiAl}(110)$ [13]. After dosing $10^{6} \mathrm{~L}$ phenol at $525 \mathrm{~K}$ (black spectrum), we see new features appear - several overlapping unresolved peaks between 60-100 meV, several overlapping peaks between $150-200 \mathrm{meV}$, and a strong peak at 350 $\mathrm{meV}$. Using reference IR absorption data from liquid phenol, we assign the new peaks to the out-of-plane ring C-C bend and out-of-plane C-H bend (60-100 meV), the C-O stretch ( 150 $\mathrm{meV}$ ), the C-C ring stretch (several unresolved peaks between 170-200 meV), and the aromatic C-H stretch (strong peak at $350 \mathrm{meV}$ )[18]. An off-specular scan (red spectrum) shows enhanced intensity in several of the peaks, particularly the $\mathrm{C}-\mathrm{H}$ stretch and the peaks between $160-200 \mathrm{meV}$, as well as a small broad peak centered at $450 \mathrm{meV}$ which is usually indicative of an $\mathrm{O}-\mathrm{H}$ stretch. The enhanced intensity in the peaks previously observed to be dipole-active indicates a tilt of the phenyl ring. The $\mathrm{O}-\mathrm{H}$ stretching observed in the offspecular spectrum is likely due to slight surface contamination over the timescale of the experiment, as each spectrum takes approximately 12 hours to record in order to achieve an acceptable signal to noise ratio. The absence of a strong O-H peak in the on-specular data (which was taken earliest, while the sample was presumably less contaminated) supports the proposed mechanism discussed earlier, showing chemisorption of the phenol through its hydroxyl substituent. 


\section{CONCLUSION}

Correlating EELS measurements of electronic and vibrational structure with EPR determinations of radical species present on titania and alumina allow us to elucidate previously undetermined features of the phenoxyl radicals formed on these two oxides. With reference to the spectrum of electronic excitations from unperturbed phenol molecules physisorbed on $\mathrm{TiO}_{2}(110)$ at $90 \mathrm{~K}$, we have shown a distinct shift of $0.3 \mathrm{eV}$ toward lower energy in the most prominent $\pi-\pi^{*}$ excitation from phenol after adsorption at $525 \mathrm{~K}$, which is the temperature regime shown in the EPR experiments to form high yields of phenoxyl radicals over both $\mathrm{TiO}_{2}$ and alumina. Given that we observe a peak at the same energy in the spectrum from phenol adsorbed at $525 \mathrm{~K}$ on alumina, we take this to be indicative of a unique change in the electronic structure of the phenoxyl radical versus the intact phenol molecule. EELS measurements alone do not permit us to determine the new molecular orbital structure of the phenoxyl radical, but the measurement of the shifted $\pi-\pi^{*}$ transition provides a starting point for density functional calculations. Additional confirmation of chemisorption and radical formation comes from the vibrational EELS measurements of phenol on alumina, which show vibrational features of the phenol molecule save for the $\mathrm{O}-\mathrm{H}$ stretching mode, which is only observed very weakly as a result of slight sample contamination, thus providing additional evidence in support of the generic mechanism of chemisorption through $\mathrm{H}_{2} \mathrm{O}$ elimination. Neither the EPR nor the EELS measurements unambiguously point to the reduction of either metal oxide after radical formation, although there is some indication in the EELS data from phenol adsorbed on $\mathrm{TiO}_{2}$ of the electrons transferred to the metal oxide from the phenol occupying the commonly observed "defect" state. Photoelectron spectroscopy measurements that probe the core level electronic structure of the alumina and titania before and after phenoxyl radical formation should determine the oxidation state of the metal ion after the chemisorption of the radical.

\section{Acknowledgments}

We acknowledge support from the National Institute of Environmental Health Sciences Superfund Research Program grant number P42 ES013648-03. PTS and NDK acknowledge partial support through the National Science Foundation under the NSF EPSCoR Cooperative Agreement No. EPS-1003897 and its REU component, with additional support from the Louisiana Board of Regents.

\section{REFERENCES}

[1]. Lomnicki S, Truong H, Vejerano E, Dellinger B. Environ. Sci. Technol. 2008; 42:4982. [PubMed: 18678037]

[2]. Vejerano E, Lomnicki S, Dellinger B. Environ. Sci. Technol. 2011; 45:589. [PubMed: 21138295]

[3]. McFerrin CA, Hall RW, Dellinger B. Journal of Molecular Structure: THEOCHEM. 2008; 848:16.

[4]. dela Cruz ALN, Gehling W, Lomnicki S, Cook R, Dellinger B. Environ. Sci. Technol. 2011; 45:6356. [PubMed: 21732664]

[5]. Khachatryan L, Vejerano E, Lomnicki S, Dellinger B. Environ. Sci. Technol. 2011; 45:8559. [PubMed: 21823585]

[6]. Khachatryan L, Dellinger B. Environ. Sci. Technol. 2011; 45:9232. [PubMed: 21942783]

[7]. Fahmy B, Ding L, You D, Lomnicki S, Dellinger B, Cormier SA. Environmental Toxicology and Pharmacology. 2010; 29:173. [PubMed: 20369027]

[8]. Balakrishna S, Lomnicki S, McAvey KM, Cole RB, Dellinger B, Cormier SA. Particle and Fibre Toxicology. 2009; 6:11. [PubMed: 19374750]

[9]. Alderman SL, Farquar GR, Poliakoff ED, Dellinger B. Environ. Sci. Technol. 2005; 39:7396. [PubMed: 16245807]

[10]. Takasuga T, Makino T, Tsubota K, Takeda N. Chemosphere. 2000; 40:1003. [PubMed: 10739038]

[11]. Seames WS. Fuel Processing Technology. 2003; 81:109. 
[12]. Cains PW, McCausland LJ, Fernandes AR, Dyke P. Environ. Sci. Technol. 1997; 31:776.

[13]. Jaeger RM, Kuhlenbeck H, Freund H-J, Wuttig M, Hoffmann W, Franchy R, Ibach H. Surface Science. 1991; 259:235.

[14]. Yoshitake M, Mebarki B, Lay T. Surface Science. 2002; 511:L313.

[15]. Song W, Yoshitake M. Applied Surface Science. 2005; 241:164.

[16]. Street SC, Guo Q, Xu C, Goodman DW. J. Phys. Chem. 1996; 100:17599.

[17]. Ari T, Güven H, Ecevit N. Journal of Electron Spectroscopy and Related Phenomena. 1995; 73:13.

[18]. Silverstein, RM.; Bassler, GC.; Morrill, TC. Spectrometric Identification of Organic Compounds. 5th ed. John Wiley \& Sons, Inc; New York: 1991. 
- EPR studies of phenol adsorption on titania and alumina show radical formation at $505 \mathrm{~K}$

- EELS of phenol/ $/ \mathrm{TiO}_{2}(110)$ at $90 \mathrm{~K}$ show $\pi-\pi^{*}$ transitions from intact molecule

- EELS of phenol/ $\mathrm{TiO}_{2}(110)$ and phenol/alumina adsorbed at $525 \mathrm{~K}$ show shift in $\pi-\pi^{*}$

- Shifted $\pi-\pi^{*}$ on single crystal corresponds to radical formation conditions in EPR 


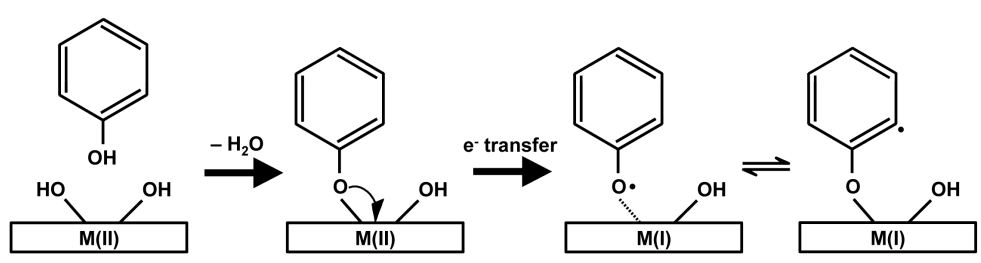

FIG. 1.

Schematic of radical formation from phenol adsorbed on a generic metal oxide. 


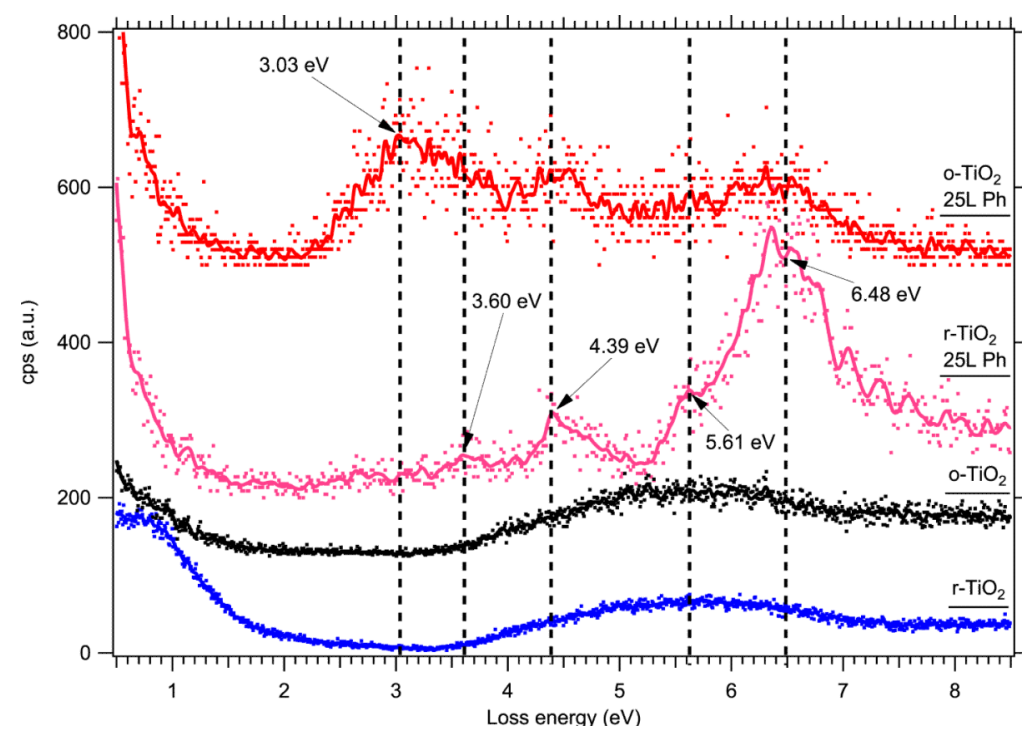

FIG. 2.

EELS data showing electronic excitations from clean and phenol-covered $\mathrm{TiO}_{2}(110)$ single crystals. From bottom to top, we show clean lightly reduced $\mathrm{TiO}_{2}(110)$, fully oxidized $\mathrm{TiO}_{2}(110), 25 \mathrm{~L}$ phenol on reduced $\mathrm{TiO}_{2}(110)$, and $25 \mathrm{~L}$ phenol on oxidized $\mathrm{TiO}_{2}(110)$. Phenol dosing, as well as each measurement, was done with the sample held at $90 \mathrm{~K}$. The dots show the raw spectra (normalized to the elastic peak from $\mathrm{r}-\mathrm{TiO}_{2}$ ), and the solid curves show the data smoothed by a binomial algorithm. Vertical dashed lines are guides to the eye. 

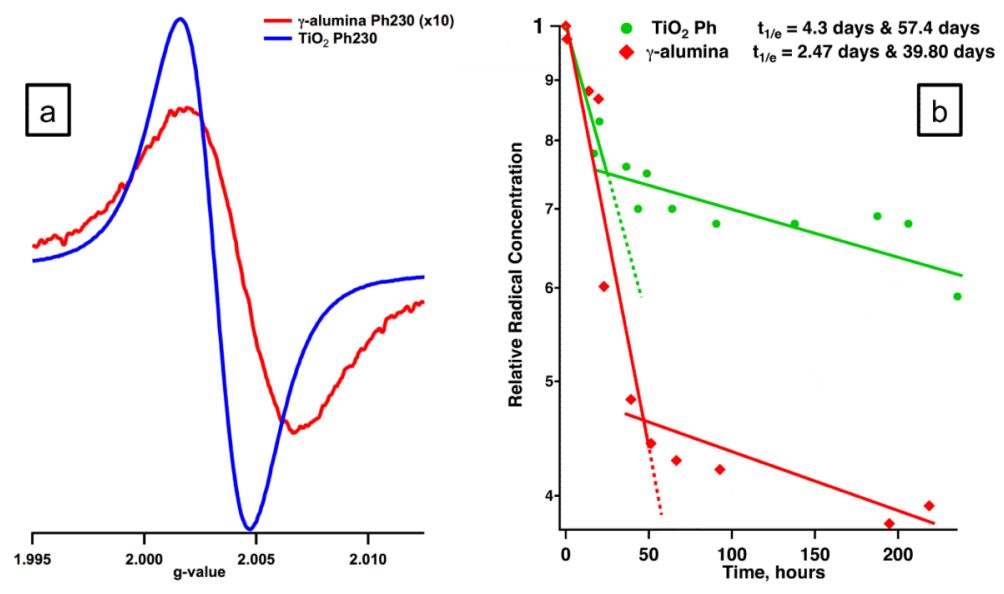

FIG. 3.

(a) EPR spectrum of phenol adsorbed on the surface of -alumina (red) and titania (blue); (b) Semi-log plot of the time decay of EPFRs from alumina (red) and titania (blue). 


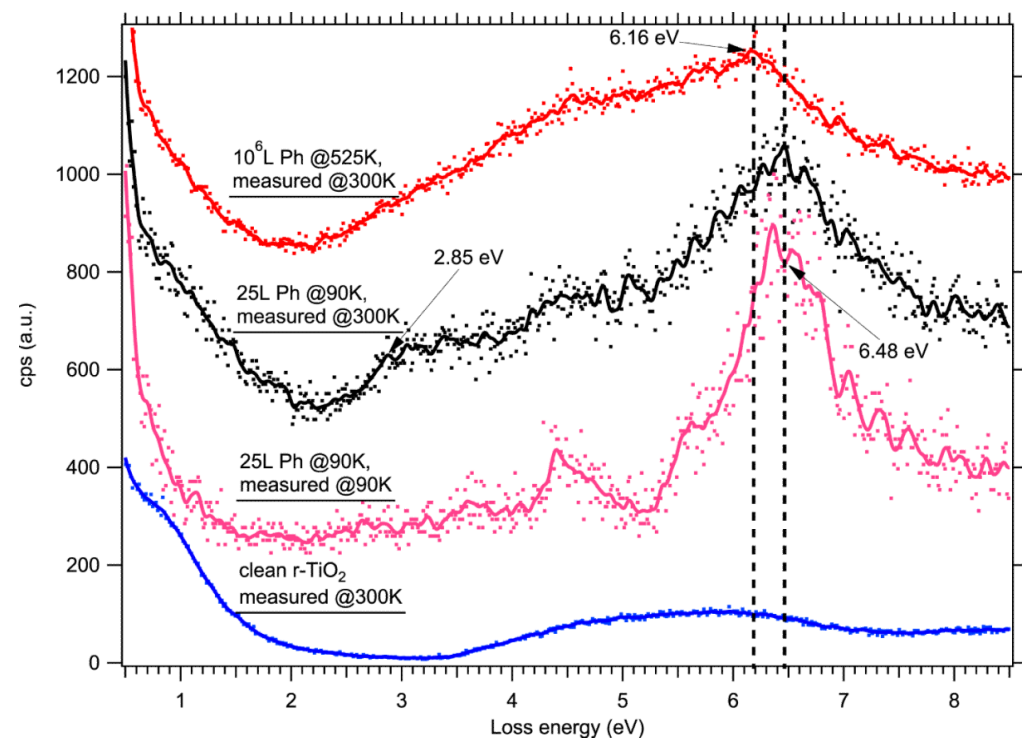

FIG. 4.

EELS data showing electronic excitations from phenol adsorbed on lightly reduced $\mathrm{TiO}_{2}(110)$ at a variety of dosing and measurement temperatures. From bottom to top, we show clean $\mathrm{r}-\mathrm{TiO}_{2}(110)$ at $300 \mathrm{~K}, 25 \mathrm{~L}$ phenol on $\mathrm{r}-\mathrm{TiO}_{2}(110)$ dosed and measured at $90 \mathrm{~K}$, $25 \mathrm{~L}$ phenol on $\mathrm{r}-\mathrm{TiO}_{2}(110)$ dosed at $90 \mathrm{~K}$ and allowed to warm to $300 \mathrm{~K}$, and $10^{6} \mathrm{~L}$ phenol dosed at $525 \mathrm{~K}$ and measured at $300 \mathrm{~K}$. As above, dots show the raw data, and solid curves show the data smoothed by a binomial algorithm. Vertical dashed lines are guides to the eye. 

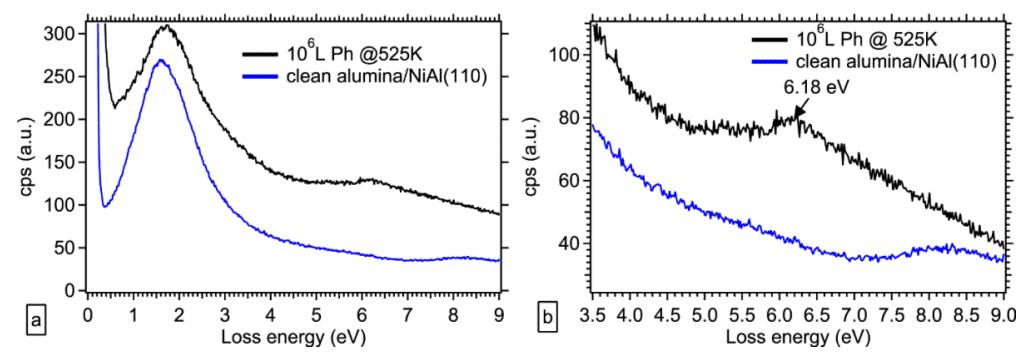

FIG. 5.

(a) EELS data showing electronic excitations on clean alumina/NiAl(110) measured at 300 $\mathrm{K}$ (blue, bottom) and $10^{6} \mathrm{~L}$ phenol adsorbed on alumina/ $\mathrm{NiAl}(110)$ at $525 \mathrm{~K}$ and measured at $300 \mathrm{~K}$ (black, top); (b) close-up of region from $3.5-9 \mathrm{eV}$ in (a). 


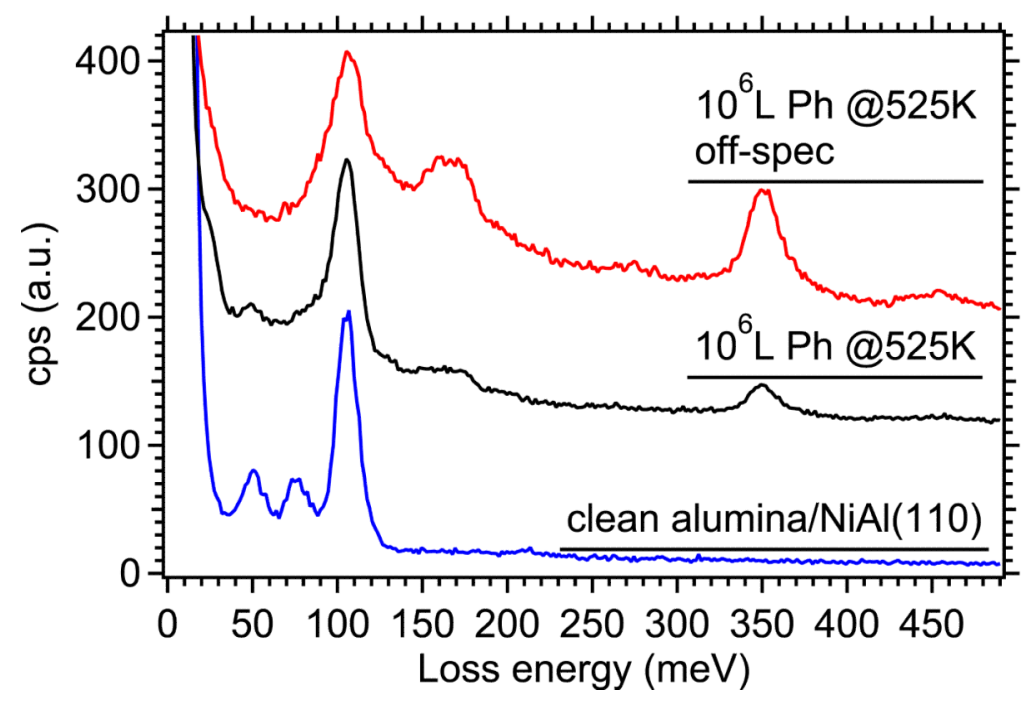

FIG. 6.

Vibrational EELS spectra of clean alumina/NiAl(110) (blue) and adsorption of $10^{6} \mathrm{~L}$ phenol on alumina/ $\mathrm{NiAl}(110)$ at $525 \mathrm{~K}$, showing both on-specular (black) and off-specular (red) geometry. In this figure, spectra have been normalized to the height of the peak at $103 \mathrm{meV}$ to more clearly show the relative intensity of vibrational peaks. All measurements were taken at room temperature. 


\section{TABLE I}

EPR spectral characteristics of the signal measured upon the exposure to phenol at $505 \mathrm{~K}$.

\begin{tabular}{|l|l|l|l|}
\hline Substrate & $\begin{array}{l}\text { g- } \\
\text { values }\end{array}$ & $\begin{array}{l}\Delta \mathbf{H}_{\text {p-p }} \\
\text { (Gauss) }\end{array}$ & Spins/gram \\
\hline -alumina & 2.0043 & 9.6 & $7.51 \times 10^{16}$ \\
\hline Titania & 2.0032 & 4.92 & $6.00 \times 10^{17}$ \\
\hline
\end{tabular}

